\title{
Isolation of cellulolytic fungi and their application for production of organic fertilizer from water hyacinth (Eichhornia crassipes)
}

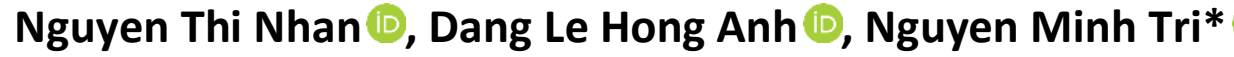

Department of Biology, Hue University of Sciences, Hue University, 530000, Thua Thien Hue, Vietnam.

How to cite

Nhan, N. T., Anh, D. L. H., Tri, N. M. (2021). Isolation of Cellulolytic Fungi and Their Application for Production of Organic Fertilizer from Water Hyacinth (Eichhornia crassipes). Biotech Studies, 30(1), $16-21$. https://doi.org/10.38042/biost.2021.30.01.03

\section{Article History}

Received 13 October 2020

Accepted 23 January 2021

First Online 23 February 2021

\section{Corresponding Author \\ Tel.: +84914031085 \\ E-mail:nminhtri@hueuni.edu.vn}

\section{Keywords}

Filamentous fungi

Cellulase

Isolate

Organic

\begin{abstract}
The purpose of this study is to isolate the cellulolytic filamentous fungi involved in the decomposition of water hyacinth to produce organic fertilizer. In this study, 13 different fungi were isolated and screened. Among them, isolate N.S8 showed the highest cellulase activity with the diameter of the clear zone of $35 \mathrm{~mm}$. The isolate N.S8 was identified by sequencing the D1/D2 region of $28 \mathrm{~S}$ rRNA coding gene. BLASTN analysis of sequenced $28 \mathrm{~S}$ rRNA segment revealed that the isolate N.S8 is Aspergillus oryzae with identity value and E-value of $100 \%$ and 0.0 , respectively. Additionally, culturing the isolate N.S8 in rice bran medium ( $\mathrm{pH} \mathrm{6.5)} \mathrm{for} 144$ hours is the optimal method of improving cellulase activity. Moreover, the use of this isolate for composting water hyacinth created an organic fertilizer with nitrogen $(\mathrm{N})$, phosphorus $\left(\mathrm{P}_{2} \mathrm{O}_{5}\right)$, and potassium $\left(\mathrm{K}_{2} \mathrm{O}\right)$ contents of $3.35 \%, 0.43 \%$ and $0.74 \%$, respectively after 45 days. Because of the high contents of nutrients, this organic fertilizer could solve the problems of fertilizer for crops with an efficiency being equivalent to that of chemical fertilizers which are known as one of the causes of soil degradation, environmental pollution and the negative effect on the quality of agricultural products.
\end{abstract}

\section{Introduction}

Fungi play an important role in the ecosystem by involving in nutrient cycling and energy flows (Buee et al., 2009). Fungi such as saprophytes convert organic matters in the soil into inorganic nutrients which plants could absorb (Morris et al., 2005). Many fungi which could successfully grow on various types of substrates and help to decompose organic matters to beneficial inorganic nutrients have been investigated (Fuchs et al., 2010).

Cellulolytic fungi are considered as the key factors to create high quality compost (Hubbe et al., 2010). Previous research indicated that the application of cellulolytic fungi increased the ability of holding water in fungal inoculated samples and balanced the $\mathrm{C}: \mathrm{N}$ ratios of cellulose waste (Hart et al., 2002; Sivaramanan et al., 2014). Additionally, the addition of microorganisms such as fungi, bacteria and other microbes was demonstrated to shorten the composting duration (Mishra et al., 2013).

Water hyacinth (Eichhornia crassipes) is a freefloating freshwater plant of the family Pontederiaceae that has a cosmopolitan distribution but are mostly found in sub-tropical and tropical countries (Agunbiade et al., 2009; Jafari et al., 2010). Water hyacinth has been proven to be a highly problematic invasive species due to its detrimental impacts of preventing sunlight and lowering disolved oxygen concentration. Controlling this plant is difficult because of its fast growth and large biomass (Akter et al., 2009). Therefore, there is a great attention of treating water hyacinth biomass. 
Water hyacinth can be processed into compost (Zimmels et al., 2006). Previous studies demonstrated that compost produced from water hyacinth is good for the yields and growths of many plants (Osoro et al., 2014). Additionally, the supplement of fungi such as Trichoderma for composting water hyacinth was proved to be useful for improving nutrition quality (Ghosh et al., 2010).

The purpose of the present research is to introduce some results about the selection of cellulolytic fungi and its application for the production of organic fertilizer from water hyacinth to create a high-quality organic fertilizer source that could increase the porosity, soil fertility and alleviate environmental pollution.

\section{Materials and Methods}

\section{Sample collection}

Soil samples (30 samples) were collected from several areas including gardens and fields in Thua Thien Hue, Vietnam. Sterile spatula and plastic bags were used for sample collection. Before being used for fungi isolation process, the samples were stored at $4{ }^{\circ} \mathrm{C}$ for 12 hours (Singh et al., 2013).

Water hyacinth (Eichhornia crassipes) was obtained from river and lakes in Thua Thien Hue Hue, Vietnam. After being collected, waterhyacinth would be dried for 5-7 days and used as raw material for the process of organic fertilizer production.

\section{Isolation of cellulolytic fungi}

The potato glucose agar (PGA) medium was used for the isolation of filamentous fungi. To isolate the fungi, $1 \mathrm{~g}$ of soil sample was suspended in $9 \mathrm{ml}$ of sterile distilled water and vortexed thoroughly. From this $10 \mathrm{ml}$ stock solution, serial dilutions were performed to $10^{-6}$. $100 \mu \mathrm{l}$ from the dilutions of $10^{-5}$ was plated in triplicates on the culture medium. Cultures were then incubated at $30{ }^{\circ} \mathrm{C}$. The growths of fungi were daily checked. Pure isolates were maintained at $4{ }^{\circ} \mathrm{C}$ in a refrigerator for further analyses (Akharaiyi et al., 2016).

\section{Determination of cellulase activity}

$25 \mathrm{ml}$ of medium, given $2 \%$ agar and $1 \%$ carboxymethylcellulose, was poured into each petri dish. Next, fungus isolates were subcultured on the medium. Cultures were then incubated at $30^{\circ} \mathrm{C}$ in the dark. After 4 days of incubation, $5 \mathrm{ml}$ of Lugol's reagent was plated on each petri dish to detect clear zones. Finally, the diameters of clear zones were obtained (Coronado-Ruiz et al., 2018).

\section{Effect of pH and temperature on cellulase activity}

The activity of cellulase was measured by changing the $\mathrm{pH}$ with $0.05 \mathrm{M}$ sodium phosphate buffer. The $\mathrm{pH}$ was varied between 5.0-7.5, after which cellulase activity was determined. The effect of temperature on cellulase activity was investigated at different temperatures of range $30-70{ }^{\circ} \mathrm{C}$ with $\mathrm{pH}$ being adjusted based on cellulase activity determined during $\mathrm{pH}$ studies (Talekar et al., 2011).

\section{Effect of culture duration}

To determine the effect of culture duration on cellulase activity, the filamentous fungi was grown on rice bran medium supplemented with carboxymethylcellulose substrate and incubated at 30 ${ }^{\circ} \mathrm{C}$. After 24-168 hours of incubation, the enzyme activity would be determined based on the diameters of clear zone (Bansal et al., 2012).

\section{Classification of filamentous fungi}

Isolates were firstly pre-classified by observing morphological features of colonies on agar plates and reproductive organs on glass slide at 40X magnification (Klich et al., 2002).

The D1/D2 region of 28S rRNA coding gene was amplified using the primer pair U1/U2 (U1FGC (5 '- CGC CCG CCG CGC GCG GCG GGC GGG GCG GGG GTG AAA TTG TTG AAA GGG AA - 3'; Sigma) and U2R (5 '- GAC TCC TTG GTC CGT GTT - 3'; Sigma)). 260 bp amplicons were then sequenced by Nam Khoa Trade Production \& Service Company Limited, Vietnam. After that, the isolate N.S8 was classified using BLASTN, with the sequenced segment as query sequence (Sandhu et al., 1995).

\section{Compost preparation}

The filamentous fungi with high cellulase activity was cultured in $250 \mathrm{ml}$ Erlenmeyer flasks containing 1\% of carboxymethylcellulose and rice bran. During the culture process, the humidity would be maintained appropriately (Tolan et al., 1999). The experiment of composting water hyacinth consisted of two treatments which are presented in Table 1.

Table 1. Treatments for composting water hyacinth

\begin{tabular}{cccc}
\hline Treatment & $\begin{array}{c}\text { Water } \\
\text { hyacinth (kg) }\end{array}$ & $\begin{array}{c}\text { Cellulolytic } \\
\text { microorganism }\end{array}$ & $\begin{array}{c}\text { Concentration } \\
\text { (\%) }\end{array}$ \\
\hline Experiment & 100 & $\begin{array}{c}\text { Strain with the } \\
\text { highest capacity of } \\
\text { degrading cellulose }\end{array}$ & 5 \\
Control & 100 & - & - \\
\hline
\end{tabular}

$100 \mathrm{~kg}$ of dried water hyacinth and $5 \mathrm{~kg}$ of fungus were well mixed. The mixture was then compacted, covered by polyethylene sheets and incubated for 45 days. Control experiment was carried out in the same way as above-mentioned without the addition of fungus.

After 45 days of incubation, the total nitrogen $(\mathrm{N})$, phosphorus $\left(\mathrm{P}_{2} \mathrm{O}_{5}\right)$ and potassium $\left(\mathrm{K}_{2} \mathrm{O}\right)$ of the compost were determined by ISO 11261:1995, wet digestion spectrophotometer $(420 \mathrm{~nm})$ and flame photometer respectively (Barton, 1948; Hesse \& Hesse, 1971).

\section{Data analysis}

The data were analyzed by ANOVA using IBM $^{\circ}$ SPSS $^{\circ}$ Statistic software (version 20). Means were compared by Duncan's test with the significance level of 
0.05. All the graphs were constructed by Microsoft ${ }^{\circledR}$ Office Excel software (2013). Each experiment was done in triplicates.

\section{Results and Discussion}

\section{Isolation and screening of cellulolytic fungi}

Thirteen filamentous fungi were isolated from different soil sources. The isolates were screened and compared for their ability of degrading cellulose. Isolates' mean clear zone diameters, obtained after 4 days of incubation, are presented in Table 2.

Table 2. Growth and enzyme activity of isolates

\begin{tabular}{ccc}
\hline Isolate's code & $\begin{array}{c}\text { Colony diameter } \\
(\mathbf{m m})\end{array}$ & $\begin{array}{c}\text { Clear zone } \\
\text { diameter }(\mathbf{m m})\end{array}$ \\
\hline N.S1 & $17(0.421)^{\mathrm{f}}$ & $17(0.234)^{\mathrm{g}}$ \\
N.S2 & $28(0.528)^{\mathrm{d}}$ & $28(0.442)^{\mathrm{d}}$ \\
N.S3 & $19(0.526)^{\mathrm{e}}$ & $19(0.521)^{\mathrm{f}}$ \\
N.S4 & $16(0.415)^{\mathrm{f}}$ & $16(0.218)^{\mathrm{g}}$ \\
N.S5 & $17(0.432)^{\mathrm{f}}$ & $19(0.322)^{\mathrm{f}}$ \\
N.S6 & $42(0.846)^{\mathrm{b}}$ & $42(0.865)^{\mathrm{c}}$ \\
N.S7 & $13(0.408)^{\mathrm{g}}$ & $17(0.831)^{\mathrm{g}}$ \\
N.S8 & $\mathbf{4 5}(\mathbf{1 . 5 2})^{\mathrm{a}}$ & $\mathbf{6 0}(\mathbf{0 . 9 6 3})^{\mathrm{a}}$ \\
N.S9 & $35(0.835)^{\mathrm{c}}$ & $45(0.958)^{\mathrm{b}}$ \\
N.S10 & $9(0.405)^{\mathrm{h}}$ & $16(0.524)^{\mathrm{h}}$ \\
N.S11 & $15(0.524)^{\mathrm{g}}$ & $15(0.519)^{\mathrm{h}}$ \\
N.S12 & $14(0.423)^{\mathrm{g}}$ & $22(0.633)^{\mathrm{e}}$ \\
N.S13 & $15(0.432)^{\mathrm{g}}$ & $23(0.631)^{\mathrm{e}}$ \\
\hline *Within a column, means having a letter in common are not significantly \\
different at the 5\% level. The values are presented as mean (standard \\
deviation).
\end{tabular}

The insignificant differences between colonies and clear zones' diameters were observed in 6 isolates namely N.S1, N.S2, N.S3, N.S4, N.S6 and N.S11. In contrast, isolates including N.S5, N.S7, N.S8, N.S9, N.S10 N.S12 and N.S13 obviously showed high cellulase activity, with the largest clear zones' diameters, $60 \mathrm{~mm}$ on average, created by N.S8. Thus, among 13 isolated fungi, 7 isolates were identified as cellulase producers. Additionally, because of the highest cellulase activity, isolate N.S8 was selected to use for further studies.

\section{Morphological characterization of the isolate N.S8}

Morphological examination showed that N.S8's colonies were initially white and then turned to the yellow color of areca flower as cultures aged. The surfaces of colonies were velvety, with clearly observed hyphae. From the microscopic observation, it is clear that the hyphae, containing septa, are olive green and branched. The conidiophore is not branched. Conidia are round and rough (Figure 1).

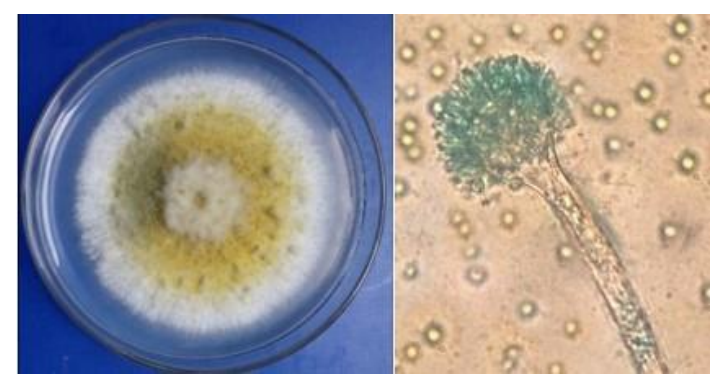

Figure 1. Features of isolate N.S8.

\section{Identification on the basis of phylogenetic analyses}

The results show that the sequenced D1/D2 region of NS.8 is highly similar to the one of A. oryzae (Accession number: AP007172.1), with the identity value and E-value of $100 \%$ and 0.0 respectively. Thus, it can be concluded that NS.8 belongs to $A$. oryzae species (Table 3 and Table 4).

Table 3. Evaluating homologous rate of $28 \mathrm{~S}$ RNA gene sequence

\begin{tabular}{cccc}
\hline $\begin{array}{c}\text { Species } \\
\text { name }\end{array}$ & $\begin{array}{c}\text { Strain } \\
\text { name }\end{array}$ & $\begin{array}{c}\text { Accession } \\
\text { number }\end{array}$ & $\begin{array}{c}\text { Homologous } \\
\text { rate (\%) }\end{array}$ \\
\hline $\begin{array}{c}\text { Aspergillus } \\
\text { oryzae }\end{array}$ & RIB40 & AP007172.1 & 100 \\
\hline
\end{tabular}

Table 4. The sequencing of the 28S rRNA gene of the isolated strain

\begin{tabular}{|c|c|c|c|}
\hline Query & 1 & CACGGGCGCGGACACCCCATCCCAGACGGGATTCTCACCCTCTCTGACGGCCCGTTCCAG & 60 \\
\hline Sbjct & 3119 & CACGGGCGCGGACACCCCATCCCAGACGGGATTCTCACCCTCTCTGACGGCCCGTTCCAG & 3060 \\
\hline Query & 61 & GGCACTTAGACAGGGGCCGCACCCGAAGCATCCTCTGCAAATTACAATGCGGACCCCGAA & 120 \\
\hline Sbjct & 3059 & GGCACTTAGACAGGGGCCGCACCCGAAGCATCCTCTGCAAATTACAATGCGGACCCCGAA & 3000 \\
\hline Query & 121 & GGAGCCAGCTTTCAAATTTGAGCTCTTGCCGCTTCACTCGCCGTTACTGAGGCAATCCCG & 180 \\
\hline Sbjct & 2999 & GGAGCCAGCTTTCAAATTTGAGCTCTTGCCGCTTCACTCGCCGTTACTGAGGCAATCCCG & 2940 \\
\hline Query & 181 & GTTGGTTTCTTTTCCTCCGCTTATTGATATGCTTAAGTTCAGCGGGTATCCCTACCTGAT & 240 \\
\hline Sbjct & 2939 & GTTGGTTTCTTTTCCTCCGCTTATTGATATGCTTAAGTTCAGCGGGTATCCCTACCTGAT & 2880 \\
\hline Query & 241 & CCGAGGTCAACCTGGAAAAAGATTGATTTGCGTTCGGCAAGCGCCGGCCGGGCCTACAGA & 300 \\
\hline Sbjct & 2879 & CCGAGGTCAACCTGGAAAAAGATTGATTTGCGTTCGGCAAGCGCCGGCCGGGCCTACAGA & 2820 \\
\hline Query & 301 & GCGGGTGACAAAGCCCCATACGCTCGAGGATCGGACGCGGTGCCGCCGCTGCCTTTGGGG & 360 \\
\hline Sbjct & 2819 & GCGGGTGACAAAGCCCCATACGCTCGAGGATCGGACGCGGTGCCGCCGCTGCCTTTGGGG & 2760 \\
\hline Query & 361 & CCCGTcccccccGGAGAGGGGACGACGACCCAACACACAAGCCGTGCTTGATGGGCAGCA & 420 \\
\hline Sbjct & 2759 & CCCGTCCCCCCCGGAGAGGGGACGACGACCCAACACACAAGCCGTGCTTGATGGGCAGCA & 2700 \\
\hline Query & 421 & ATGACGCTCGGACAGGCATGCCCCCCGGAATACCAGGGGGCGCAATGTGCGTTCAAAGAC & 480 \\
\hline Sbjct & 2699 & ATGACGCTCGGACAGGCATGCCCCCCGGAATACCAGGGGGCGCAATGTGCGTTCAAAGAC & 2640 \\
\hline Query & 481 & TCGATGATTCACGGAATTCTGCAATTCACACTAGTTATCGCATTTCGCTGCGTTCTTCAT & 540 \\
\hline Sbjct & 2639 & TCGATGATTCACGGAATTCTGCAATTCACACTAGTTATCGCATTTCGCTGCGTTCTTCAT & 2580 \\
\hline Query & 541 & CGATGCCGGAACCAAGAGATCCATTGTTGAAAGTTTTAACTGATTGCGATACAATCAACT & 600 \\
\hline Sbjct & 2579 & CGATGCCGGAACCAAGAGATCCATTGTTGAAAGTTTTAACTGATTGCGATACAATCAACT & 2520 \\
\hline Query & 601 & CAGACTTCACTAGATCAGACAGAGTTCGTGGTGTCTCCGGCGGGCGCGGGCCCGGGGCTG & 660 \\
\hline Sbjct & 2519 & CAGACTTCACTAGATCAGACAGAGTTCGTGGTGTCTCCGGCGGGCGCGGGCCCGGGGCTG & 2460 \\
\hline Query & 661 & AGAGCCCCCGGCGGCCATGAATGGCGGGCCCGCCGAAGCAACTAAGGTACAGTAAACACG & 720 \\
\hline
\end{tabular}


Determination of the suitable conditions for cellulase synthesis

\section{Effect of culture duration}

It is illustrated in Figure 2 that when the culture duration was increased, the cellulase activity of $A$. oryzae rose. However, when the optimal culture duration was exceeded, the enzyme activity began to drop. The maximum cellulase activity was attained after $144 \mathrm{~h}$ of incubation with a clear zone diameter of 38.67 $\mathrm{mm}$ on average.

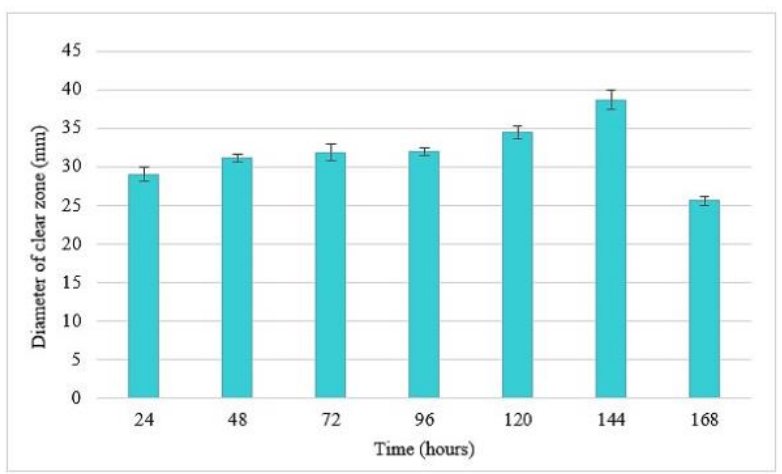

Figure 2. Effect of time on A. oryzae cellulase activity. Error bars indicate standard deviation.

Compared to the previous research, differences were observed in the results of our present study. Specifically, according to Acharya et al. (2008), the highest cellulase activity was obtained after 96 hours of fermentation using $A$. niger (Acharya et al., 2008). Additionally, another research on cellulase production by $A$. niger from coastal mangrove debris conducted by Devanathan et al. (2007) also indicated that the optimal fermentation duration is 96 hours (Devanathan et al., 2007). Thus, all the above-mentioned results proved that the culture duration can affect the ability of producing cellulase of the filamentous fungi. Moreover, the optimal culture duration and enzyme amount are different among fungus strains (Nochure et al., 1993).

\section{Effect of $\mathrm{pH}$}

As it is highlighted in Figure 3, the highest cellulase activity was obtained at $\mathrm{pH} 6.5$ with the average clear zone diameter of $37.55 \mathrm{~mm}$. According to Anita et al. (2009), the optimal $\mathrm{pH}$ for cellulase activity produced by A. heteromorphus is 6.0 (Anita et al. 2009). Furthermore, in a study conducted by Akiba et al. (1995), the authors concluded that the optimal $\mathrm{pH}$ for cellulase activity from A. niger is 6.0-7.0, and the stable $\mathrm{pH}$ range is 5.0-10.0 (Akiba et al., 1995). These different results might be caused by the genetic differences within the same genus (Acharya et al., 2008).

\section{Effect of temperature}

The effect of temperature on cellulase activity was determined in the range of $30-70{ }^{\circ} \mathrm{C}$. As illustrated in Figure 4 , the optimum temperature was $40^{\circ} \mathrm{C}$. Beyond
$40{ }^{\circ} \mathrm{C}$, thermostability decreased, possibly due to thermal denaturation of enzyme. The results obtained from this study are similar to the findings of Ali et al. (1991) who concluded that the optimal temperature for cellulase activity from $A$. niger "Z10" and $A$. terreus was at $40^{\circ} \mathrm{C}$. Loss of cellulase activity was observed beyond $40^{\circ} \mathrm{C}$ and $50^{\circ} \mathrm{C}$ (Ali et al., 1991).

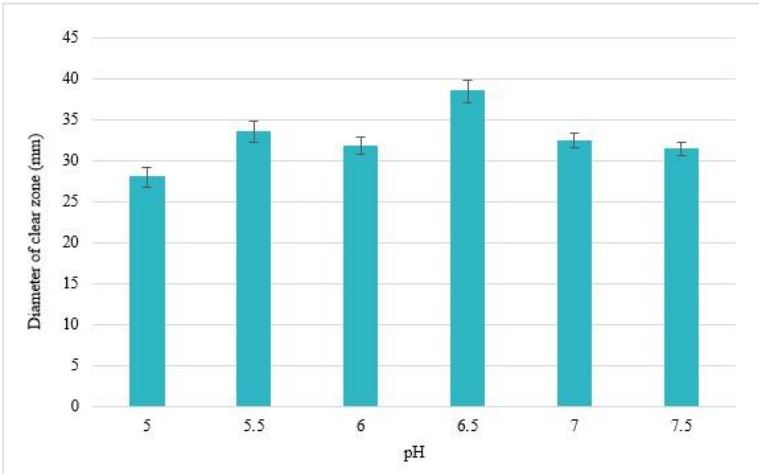

Figure 3. Effect of $\mathrm{pH}$ on A. oryzae cellulase activity. Error bars indicate standard deviation.

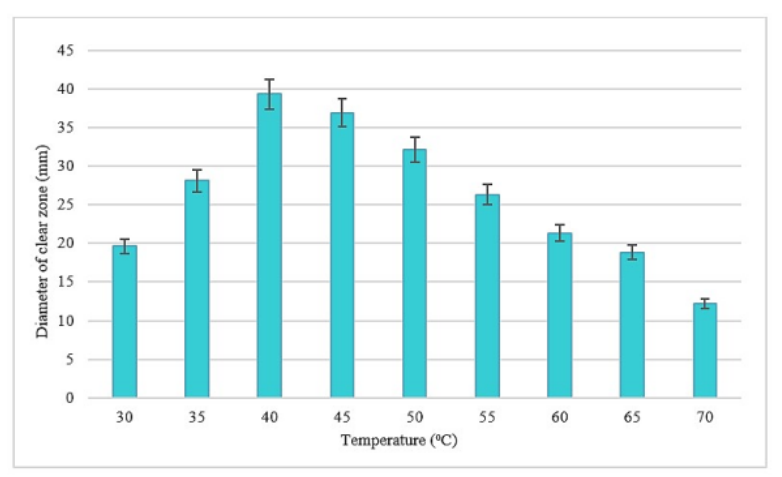

Figure 4. Effect of temperature on A. oryzae cellulase activity. Error bars indicate standard deviation.

Creating organic fertilizer from water hyacinth and $A$. oryzae "N.S8"

After 6 days of culturing the fungus in the optimized condition, $100 \mathrm{~kg}$ of dried water hyacinth and $5 \mathrm{~kg} \mathrm{~A}$. oryzae were mixed. After 45 days of incubation, chemical parameters of the organic fertilizer were shown in Table 3.

The provided results in Table 5 indicated that after being incubated, the total $\mathrm{N}, \mathrm{P}$, and $\mathrm{K}$ contents in all treatments increased. However, the contents of N, P, K in the treatment containing microorganisms was higher than those of the control with $1.53 \%, 0.19 \%$ and $0.38 \%$, respectively.

The nutrient compositions of organic fertilizer from water hyacinth in the present research are higher compared to that in the previous research of Thanaporn et al. (2019) who concluded that the ranges of chemical parameters in the liquid organic fertilizer produced from agricultural residues and industrial wastes are 0.14 $0.33 \%$ (total $\mathrm{N}$ ), $0.002-0.017 \%$ (total $\mathrm{P}_{2} \mathrm{O}_{5}$ ) and 0.81 $11.8 \%$ (total $\mathrm{K}_{2} \mathrm{O}$ ) (Thanaporn et al., 2019). 
Table 5. Analysis results of total N, P, K contents in organic fertilizer sample

\begin{tabular}{ccccc} 
& \multicolumn{2}{c}{ Before incubation } & \multicolumn{2}{c}{ After incubation } \\
\cline { 2 - 5 } $\begin{array}{c}\text { Content } \\
\text { (\%) }\end{array}$ & Control & $\begin{array}{c}\text { Experimental } \\
\text { treatment } \\
\text { (Supplemented } \\
\text { with } 5 \% \text { A. } \\
\text { oryzae "N.S8") }\end{array}$ & Control & $\begin{array}{c}\text { Experimental } \\
\text { treatment } \\
\text { (Supplemented } \\
\text { with } 5 \% \text { A. } \\
\text { oryzae "N.S8") }\end{array}$ \\
\hline Total N & 1.42 & 1.42 & 1.53 & 3.35 \\
Total P & 0.16 & 0.16 & 0.19 & 0.43 \\
Total K & 0.36 & 0.36 & 0.38 & 0.74 \\
\hline
\end{tabular}

\section{Conclusion}

Thirteen filamentous fungi with the ability of degrading cellulose were isolated from different soil sources in which the isolate N.S8 showed the highest cellulase activity with the average diameter of clear zone of $35 \mathrm{~mm}$. The results of classification indicated that this isolate is $A$. oryzae.

The optimal culture duration and $\mathrm{pH}$ for growth and development of $A$. oryzae "N.S8" in rice bran medium are 144 hours and $\mathrm{pH} 6.5$.

The use of $A$. oryzae "N.S8" for composting water hyacinth created an organic fertilizer with nitrogen $(\mathrm{N})$, phosphorus $\left(\mathrm{P}_{2} \mathrm{O}_{5}\right)$, and potassium $\left(\mathrm{K}_{2} \mathrm{O}\right)$ contents of $3.35 \%, 0.43 \%$ and $0.74 \%$, respectively after 45 days.

\section{References}

Acharya, P. B., Acharya, D. K., \& Modi, H. A. (2008). Optimization for cellulase production by Aspergillus niger using saw dust as substrate. African Journal of Biotechnology, 7(22), 4147-4152. http://doi.org./10.5897/AJB08.689

Agunbiade, F. O., OluOwolabi, B. I., \& Adebowale, K. O. (2009). Phytoremediation potential of Eichornia crassipes in metal contaminated coastal water. Bioresource Technology, 100, 4521-4526. https://doi.org/10.1016/j.biortech.2009.04.011

Akharaiyi F. C \& Abiola M. A. (2016). Isolation and cultivation of fungi with agrowastes formulated media. Der Pharma Chemica, 8(9), 56-62.

Akiba, S., Kimura, Y., Yamamoto, K., \& Kumagai, H. (1995). Purification and characterization of a protease-resistant cellulase from Aspergillus niger. Journal of Fermentation and Bioengineering, 79(2), 125-130. https://doi.org/10.1016/0922-338X(95)94078-6

Akter, A. \& Zuberi, M. I. (2009). Invasive alien species in Northern Bangladesh: identification, inventory and impacts. International journal of biodiversity and conservation, 1(5), 129-134.

Ali, S., Sayed, A., Sarker, R. I., \& Alam, R. (1991). Factors affecting cellulase production by Aspergillus terreus using water hyacinth. World Journal of Microbiology and Biotechnology, 7(1), 62-66.

Anita, S., Namita, S., Narsi, R., \& Bishnoi. (2009). Production of cellulases by Aspergillus heteromorphus from wheat straw under submerged fermentation. International Journal of Environmental Science and Technology, 1, 2326. https://doi.org/10.5281/zenodo.1055807

Bansal, N., Tewari, R., Soni, R., \& Soni, S. K. (2012). Production of cellulases from Aspergillus niger NS-2 in solid state fermentation on agricultural and kitchen waste residues.
Waste Management, 32(7), 1341-1346. https://doi.org/10.1016/j.wasman.2012.03.006

Barton, C. J. (1948). Photometric analysis of phosphate rock. Analytical Chemistry, 20(11), 1068-1073. https://doi.org/10.1021/ac60023a024

Buee, M., Reich, M., Murat, C., Morin, E., Nilsson, R. H., Uroz, S. \& Martin, F. (2009). 454 Pyrosequencing analyses of forest soils reveal an unexpectedly high fungal diversity. New Phytologist, 184, 449-456. https://doi.org/10.1111/j.1469-8137.2009.03003.x

Coronado-Ruiz, C., Avendaño, R., Escudero-Leyva, E., ConejoBarboza, G., Chaverri, P., \& Chavarría, M. (2018). Two new cellulolytic fungal species isolated from a 19thcentury art collection. Scientific Reports, 8(1). https://doi.org/10.1038/s41598-018-24934-7

Devanathan, A., Shanmugam, T., Balasubramanian., \& Manivannan, S. (2007). Cellulase production by Aspergillus niger isolated from coastal mangrove debris. Trends in Applied Sciences Research, 2, 23-27. https://doi.org/10.3923/tasr.2007.23.27

Fuchs, J. G. (2010). Interactions between beneficial and harmful micro-organisms: from the composting process to compost application. In: Microbes at work. From wastes to resources (Eds. Insam H, Frank-Whittle IH, Goberna M). Springer, Heidelberg, 213-230. https://doi.org/10.1007/978-3-642-04043-6 11

Ghosh, D. (2010). Water hyacinth, befriending the noxious weed. Science Reporter, 47(12), 46-48.

Hart, T. D., De Leij, F.A.A.M., Kinsey, G., Kelley, J. \& Lynch, J. M. (2002). Strategies for the isolation of cellulolytic fungi for composting of wheat straw. World Journal of Microbiology and Biotechnology, 18(5), 471-480. https://doi.org/10.1023/A:1015519005814

Hesse, P. R., \& Hesse, P. R. (1971). Textbook of soil chemical analysis. William Clowes and Son, London. https://doi.org/10.1017/S0014479700005202

Hubbe, M. A., Nazhad, M. \& Sánchez, C. (2010). Composting as a way to convert cellulosic biomass and organic waste into high-value soil amendments: A review. BioResources, 5(4), 2808-2854. https://doi.org/10.15376/biores.5.4.2808-2854

Jafari, N. (2010). Ecological and socio-economic utilization of water hyacinth (Eichhornia crassipes Mart Solms). Journal of Applied Sciences and Environmental Management, 90, 43-49. https://doi.org/10.4314/jasem.v14i2.57834

Klich M. A. (2002). Identification of common Aspergillus species. Centraalbureau Voor Schimmelcultures CBS, Utrecht, The Netherlands.

Mishra, B. K. \& Nain, L. (2013). Microbial activity during rice straw composting under co-inoculation of cellulomonas cellulans and Phanerochaete chrysosporium. International Journal of ChemTech Research, 5(2), 795801.

Morris, S. J. \& Robertson, G. P. (2005). Linking function between scales of resolution. In: The Fungal community: its organization and role in the ecosystem (Eds. Dighton J, White JF, Oudemans P). Taylor and Francis, Boca Raton, USA, 13-26.

Nochure, S. V., Roberts, M. F., \& Demain, A. L. (1993). True cellulase production by C.thermocellum grown on different carbon sources. Biotechnology Letters, 15(6), 641-646.

Talekar, S., Ghodake, V., Chavare, S., Ingrole, R., Kate, A., Magdum, S., \& Pillai, M. (2011). Production and 
characterization of cellulase by local fungal isolate of India using water hyacinth as carbon source and reuse of fungal biomass for dye degradation. International Journal of Engineering, Science and Technology, 3 (4), 3236-3241.

Thanaporn, P., \& Nuntavun, R. (2019). Liquid organic fertilizer production for growing vegetables under hydroponic condition. International Journal of Recycling of Organic Waste in Agriculture, 8, 369-380. https://doi.org/10.1007/s40093-019-0257-7

Tolan, J. S., \& Foody, B. (1999). Cellulase from submerged fermentation. In: Advances in Biochemical Engineering. Biotechnology, 65, 41-67. https://doi.org/10.1007/3540-49194-5 3

Osoro, N. O., Kawaka, F., Naluyange, V., Ombori, O., Muoma, J. O., Amoding, A. \& Maingi, J. M. (2014). Effects of water hyacinth (Eichhornia crassipes [Mart.] Solms.) compost on growth and yield of common beans (Phaseolus vulgaris) in Lake Victoria Basin. European International Journal of Science and Technology, 3(7), 173-186.
Sandhu, G. S., Kline, B. C., Stockman, L., \& Roberts, G. D. (1995). Molecular probes for diagnosis of fungal infections. Journal of Clinical Microbiology, 33, 2913-2919. http://doi.org/10.1128/JCM.33.11.2913-2919.1995

Singh, S., Moholkar, V. S., \& Goyal, A. (2013). Isolation, Identification, and Characterization of a Cellulolytic Bacillus amyloliquefaciens Strain SS35 from Rhinoceros Dung. ISRN Microbiology, 2-7. https://doi.org/10.1155/2013/728134

Sivaramanan, S. (2014). Isolation of cellulolytic fungi and their degradation on cellulosic agricultural wastes. Journal of Academia and Industrial Research, 2(8), 458-463.

Zimmels, Y., Kirzhner, F. \& Malkovskaya, A. (2006). Application of Eichhornia crassipes and Pistia stratiotes for treatment of urban sewage in Israel. Journal of Environmental Management, 81, 420-428. https://doi.org/10.1016/i.jenvman.2005.11.014 